\title{
Gender Differences in Adjustment to Bereavement: An Empirical and Theoretical Review
}

\author{
Margaret Stroebe, Wolfgang Stroebe, and Henk Schut \\ Utrecht University
}

\begin{abstract}
The loss of a marital partner results in substantial increases in morbidity and mortality among both men and women, but the effects are relatively greater for widowers than for widows in the acute grieving period. Evidence is reviewed, and explanations of the pattern are examined. An interpretation in terms of gender differences in social support (cf. M. Stroebe \& W. Stroebe, 1983), although plausible, has not yet been empirically confirmed. Likewise, with respect to gender differences in coping styles, women are more confrontive and expressive of their emotions than men, but there has been little validation of the generally accepted grief work hypothesis (working through grief by women brings about their better recovery). Cognitive processes underlying effective coping with bereavement are analyzed, and a stressor-specific framework, the dualprocess model of coping with loss, is suggested to help explain gender differences in health outcomes.
\end{abstract}

One of the most intriguing phenomena to emerge in the short history of the scientific study of bereavement is the existence of patterns of gender differences in reactions. An early review of the literature (M. Stroebe \& Stroebe, 1983) suggested that men suffer relatively greater health consequences than women and that this difference is due to higher levels of social support received by widows than widowers. There are good reasons to reassess these claims. A substantial body of new evidence has become available with regard to both the pattern of gender differences and the psychological mechanism assumed to account for these differences. We argue here that the new empirical evidence is generally consistent with our claim that men suffer relatively greater health consequences from bereavement than women but not with the explanation in terms of gender differ-

Margaret Stroebe, Wolfgang Stroebe, and Henk Schut, Research Institute for Psychology \& Health, Utrecht University, Utrecht, the Netherlands.

We wish to thank Susan Folkman and Vicki Helgeson for their valuable comments on an earlier version of this article and Maaike Terheggen for assistance in the preparation of the article.

Correspondence concerning this article should be addressed to Margaret Stroebe, Research Institute for Psychology \& Health, Department of Psychology, Utrecht University, P.O. Box $80.140,3508$ TC Utrecht, the Netherlands. Electronic mail may be sent to M.Stroebe@ fss.uu.nl. ences in the levels of social support received by widowers and widows. Thus, in this article, we develop a new explanation based on gender differences in coping with grief.

Our focus is on partner loss, because this is the type of bereavement for which there is the most empirical research, and on early bereavement, because, over time, levels of distress and debility generally decline to become equivalent to those for nonbereaved samples (M. Stroebe, Stroebe, \& Hansson, 1993). As in our earlier review (M. Stroebe \& Stroebe, 1983), we have conceived of gender differences in terms of relative risk. The relative risk of a disease is defined in epidemiology as the ratio of the chance of disease in individuals exposed to a risk factor to the risk of disease in individuals without exposure (Jeffery, 1989). Thus, by comparing the disease risk of bereaved men or women with that of a matched nonbereaved control group, we can assess the relative risk attributable to bereavement for a given health risk among widowers and widows. Our analysis of gender differences is based on comparison of the relative magnitude of widowed-married ratios (i.e., relative risks for widowers and widows) across different health consequences. These patterns provide important clues for the analysis of theoretical mechanisms.

It is worth noting that risk can also be assessed from a population perspective. Population-attributable risk is the number of excess 
cases of a disease in a population that can be attributed to a particular risk factor. The number of excess cases in a given population attributable to a given risk factor is only partly dependent on relative risk. Another important determinant is the frequency with which a risk factor or combination of risk factors occurs in a given population. The widow to widower ratio frequently reaches $4: 1$ (U.S. Department of Health \& Human Services, 1985), because women live longer than men, tend to marry men older than they are themselves, and remarry after bereavement less frequently than men; thus, there are likely to be more excess cases among widows than among widowers. As a result, the population-attributable risk is higher for widows than for widowers. Thus, the fact that clinicians are likely to encounter a larger proportion of depressed widows than widowers because of the higher proportion of widows in the population (population-attributable risk) is not at all inconsistent with the fact that widowers have a higher relative risk of depression after bereavement than widows.

\section{Gender Differences in Health Consequences of Bereavement: The Empirical Evidence}

There is a fairly sound body of evidence on the detrimental health consequences of bereavement for widowed persons in general. When comparisons are made with still-married individuals, as suggested earlier, detrimental effects to physical as well as mental health for both widowed men and women are evident. Rates of distress and depression, use of medication, physical illness health measures (e.g., number of days sick and visits to doctors), and even mortality are generally reported to be higher for those who are widowed than for comparable still-married individuals (Carter \& Glick, 1976; Gove, 1972a, 1972b, 1973; Osterweis, Solomon, \& Green, 1984; Parkes, 1996; W. Stroebe \& Stroebe, 1987; W. Stroebe, Stroebe, \& Schut, 1993). The gender difference emerges when one examines the relative magnitude of the widowed to married ratios, and this too pertains across a broad spectrum of mental and physical health consequences.

\section{Distress and Depressive Symptomatology}

Most bereaved people feel distressed and depressed after the loss of a loved person (Parkes, 1996; W. Stroebe \& Stroebe, 1987). Although these reactions may, in some cases, be severe enough to require psychiatric or medical treatment, they are generally considered to be normal reactions to the death of a loved person, ones that will abate over the course of time, usually without intervention (cf. Clayton, 1990). Thus, it is important to consider studies of distress and depression separately from the general category of mental illness. Most bereaved people who are depressed do not seek treatment and would not be classified as mentally ill.

Measures used to assess such effects vary from established, validated depression scales, such as the Beck Depression Inventory (Beck, 1967) or the Center for Epidemiologic Studies Depression Scale (CES-D; Radloff, 1977), to measures of distress constructed specifically for a particular study. Likewise, studies vary from small cohort investigations conducted longitudinally to cross-sectional surveys of depression rates. Because the aim here is to identify general patterns of gender differences by widowed versus married mental health status, this broad range of study types is covered in this section.

A further observation is necessary before we review the studies. Reactions of distress and depression are not only grief specific, showing endorsement of items on grief symptom scales such as those focusing on upset at the loss of one's spouse, distress about being left alone, or loneliness in the absence of one's partner (e.g., the Grief Experience Inventory; see Sanders, Mauger, \& Strong, 1991), but also generalized, showing elevated rates among bereaved individuals on depression scales (e.g., the Beck Depression Inventory; see Beck, 1967) that do not make any specific reference to grief. Clearly, no comparison of bereaved and married individuals' responses is possible when griefspecific scales are used, whereas such comparisons are possible on general scales of depression. Can we draw conclusions about relative upset among widows and widowers from responses on specific scales? This is indeed problematic, because women in general and widowed women in particular not only have higher depression levels but are also more acknowl- 
edging and expressive of their emotions than men (Derlega, Metts, Petronio, \& Margulis, 1993; Notarious \& Johnson, 1982; Pennebaker \& Roberts, 1992; Shields, 1991). With these assessment problems in mind, we turn to the empirical studies.

Support for the hypothesis that widowers are relatively more distressed than widows by the loss of their spouse was provided in two early studies, each of which has become a classic contribution although involving very different types of design. In a community survey of depression involving nearly 2,500 White persons, Radloff (1975) found a Gender $\times$ Marital Status interaction on level of depression. Although married women were more depressed than married men, widowed men were more depressed than widowed women. Thus, despite the higher depression rates of women, men became relatively more depressed on bereavement. In the second study, a small, in-depth investigation of a sample of younger bereaved individuals (49 widows and 19 widowers), Glick, Weiss, and Parkes (1974) found, 2 to 4 years after bereavement, that widowers had taken longer to recover than widows. Widows had higher depression scores than married women 1 year after bereavement; at the later follow-up, however, they were no more depressed than the married women, whereas widowers remained significantly more depressed than married men.

More recent studies have confirmed this pattern, although it must be noted that surprisingly few studies have compared depression levels by gender for widowed and married individuals. A stringent test of the gender difference was provided by Umberson, Wortman, and Kessler (1992), who used the results of a large national survey to examine long-term differences in vulnerability to depression among those who were conjugally bereaved. These authors found that in comparisons with same-gender married individuals, widowers were relatively more affected by loss than widows. The same pattern was reported in a telephone survey of 746 elderly men (222 married and 38 widowed) and women (253 married and 233 widowed) conducted in two U.S. states. Widowhood had "a substantially stronger effect on depression for men than women" (Lee, Willetts, \& Seccombe, 1998, p. 622 ), and the interaction was not reduced by the introduction of measures of social support (con- tact with friends and church membership) into the regression equation.

Similar gender differences were also found in a large-scale, methodologically sophisticated study conducted by Siegel and Kuykendall (1990), even though this study focused on the impact of the recent death of a close (nonspouse) family member on depressed mood. Respondents were more than 800 elderly men and women of whom $14 \%$ had recently suffered the loss of a close family member. When loss status was entered into a regression analysis, higher levels of depressive symptomatology were found among men but not among women. Thus, losing a close family member within the previous 6 months resulted in a greater increase in depressed mood among men than women. Important here is a further pattern that emerged when the researchers assessed whether marital status would moderate the impact of the recent death of a (nonspouse) family member. This analysis resulted in a significant Marital Status $\times$ Loss interaction for men but not for women; it was the widowed men who, in comparison with their married counterparts, reacted with elevated depression levels to the loss of a close family member. Siegel and Kuykendall (1990) thus identified elderly widowers as a particularly vulnerable group, one that is at greater relative risk of depression (and, they argued, consequent physical health detriments) than their female counterparts.

The greater relative risk of depression for widowers has also been demonstrated outside the United States in studies conducted in Great Britain (Cramer, 1993) and the Netherlands (Nieboer, Lindenberg, \& Ormel, 1998; Van Grootheest, Beekman, Broesse van Groenou, \& Deeg, 1999). Using data from a nationally representative cross-sectional survey of 9,003 British adults and controlling for age, education, and income, Cramer (1993) found that widowers had significantly higher rates of psychological distress (as measured by the General Health Questionnaire; Goldberg \& Hillier, 1979) relative to married men than did widows relative to married women. In fact, the rates of widows did not show a significant elevation. Similarly, Van Grootheest et al. (1999), in a large-scale community study of 2,626 widowed and married men and women 55 to 85 years of age conducted in the Netherlands, found widowhood to be associated with higher levels of depressive 
symptomatology (as measured by the CES-D). This association was stronger for men than for women. Interestingly, the effect was mediated by different types of environmental stressors for widows (e.g., network size) and widowers (e.g., emotional support received). Furthermore, widows appeared to adapt to widowhood more successfully over time. Finally, Nieboer et al. (1998), who analyzed the consequences of widow(er)hood in regard to depressive symptomatology in a sample of 1,252 widowed respondents in the Netherlands, also reported relatively higher depression scores for widowers than for widows. The data were cross-sectional and were analyzed according to a cutoff point indicating recency of bereavement (less than vs. more than 2 years). The gender difference in bereavement outcome was significant for those recently bereaved but not for those who had lost their partners more than 2 years earlier. This is in contrast to the results of Van Grootheest et al. (1999), Glick et al. (1974), and recent comparisons made by Bierhals et al. (1996; see also Chen et al., 1999) focusing on the temporal course of grief symptomatology among widowers and widows (with no control groups). The reason for this discrepancy is unclear but is not of central concern, because our focus is on the acute grieving period.

A few authors have argued that widows suffer greater depression on bereavement than widowers, concluding that female elevations on depression during bereavement exceed the corresponding male elevations (Carey, 1977; Gilbar \& Dagan, 1995; Jacobs, Kasl, Ostfeld, Berkman, \& Charpentier, 1986). On examination, it becomes evident that these studies failed to include nonbereaved control groups. Thus, they probably confounded the general gender difference in depression (i.e., absolute risk) —namely, that women have higher depression rates than men-with the bereavement-specific effect (i.e., relative risk). As argued earlier, the general gender difference in the base rate for depression must be controlled to reveal the gender difference that can be attributed to the impact of bereavement. Failure to do so results in a confounding of the absolute risk in depression with the bereavement-specific or relative risk. For example, Carey $(1977,1979)$ has frequently been cited in the literature as providing evidence that widows are at higher risk of depression than widowers. However, this conclusion was based on a direct comparison of the scores on an eight-item measure of "adjustmentdepression" of 78 widows and 41 widowers. This finding, therefore, might merely be a reflection of the higher depression rate among women in the population. As such, the interpretation may in fact be correct but should not be interpreted in terms of more extreme reactions of women than men to the loss of a partner. Likewise, Gilbar and Dagan (1995) concluded, from their study of 43 widows and 24 widowers, that widows suffered more than widowers. They found no statistically significant differences between widowers' and widows' scores on a depression measure, but they found that widowers reported fewer difficulties in coping with their loss than did widows, as measured with the Texas Revised Inventory of Grief (Faschingbauer, Zisook, \& De Vaul, 1987). There were no nonbereaved controls. The conclusion drawn by Gilbar and Dagan (1995) that men cope better may be more in line with the observed general tendency of men to acknowledge or report less depressive symptomatology (cf. Meshot \& Leitner, 1993) than an indication that they are having a less difficult time with their bereavement. Control group comparisons would have clarified this issue.

Other studies have claimed similar levels of distress for bereaved men and women (Bornstein, Clayton, Halikas, Maurice, \& Robbins, 1973; Clayton, Halikas, \& Maurice, 1972; Gallagher, Breckenridge, Thompson, \& Peterson, 1983; Lund, Caserta, \& Dimond, 1986; Weisman \& Klerman, 1977). Lund et al. (1986) made gender comparisons among widowed individuals but failed to compare rates with those for nonbereaved men and women. These authors concluded that there were no substantial differences with respect to depression between widowed men and women in their study. Although literally this is a correct inference from the data, the suggestion it raises is that there are no differences in reactions to loss. Therefore, a criticism similar to that raised earlier applies: Because women in general display more distress and symptoms of depression, a finding of no difference could indeed indicate relative increases for widowers. The early Clayton studies suffered from the same methodological shortcoming (see M. Stroebe \& Stroebe, 1983).

A number of interview studies that included married control groups but still failed to reveal 
a Gender $\times$ Marital Status interaction may have been subject to selection bias. For example, there is some indication that the failure of our own study to show a Gender $\times$ Marital status interaction may have been due to selection bias among interview participants (W. Stroebe \& Stroebe, 1993; W. Stroebe, Stroebe, \& Domittner, 1988). Because our study had a relatively low response rate, we asked individuals who refused to be interviewed whether they were willing to complete a mailed questionnaire, and a reasonable proportion of respondents agreed. This mailed questionnaire contained a measure of depression. Findings indicated that the widowers who refused interviews (but filled in the postal questionnaire) were significantly more depressed than those who accepted, whereas the opposite pattern prevailed for widows (M. Stroebe \& Stroebe, 1989). We accounted for this finding in terms of social norms that make it embarrassing for depressed men but not women to show strong emotions (e.g., cry) in an interview setting. This "dropout" effect, in which less depressed widowers and more depressed widows were selected into the interviews, would account for the fact that interviewed widowers did not show the excesses in comparison with widows observed in the studies reviewed earlier.

One other study, an investigation of elderly widows and widowers conducted by Gallagher et al. (1983), compared depression levels of 212 recently widowed individuals $(99$ men and 113 women) with those of married, same-gender controls ( 84 men and 78 women) and revealed no Gender $\times$ Marital Status interaction. This study, then, also observed the methodological requirements with respect to controls and still failed to support the pattern of relatively higher levels of depression among widowers reported in the other methodologically sound studies. Is this strong evidence against the hypothesis of relatively greater excesses for widowers? Although this could be the case, there are also reasons to argue otherwise. The study had a high rejection rate (only $30 \%$ responded to the first mailing; for more information, see Gallagher-Thompson, Futterman, Farberow, Thompson, \& Peterson, 1993), so selection biases must be considered. As was the M. Stroebe and Stroebe (1989) investigation, it was an interview study, and the results would suggest that here, too, more depressed widowers and less depressed widows may have been selected out of the study. Mortality patterns, discussed later, support this hypothesis (see Gallagher-Thompson et al., 1993).

Hays, Kasl, and Jacobs (1994) reported on the course of distress among spouses $(N=440)$ of patients hospitalized for serious illness or surgery, some of whom died during the 2-year follow-up period. Few gender differences were observed, but, at 25 months, the widows who had remained in the study were more depressed than widowers. This study involved extensive interviewing and may thus be subject to the same Gender $\times$ Attrition interaction effect noted earlier (selection out of more distressed men). There were, in fact, high nonresponse and dropout rates, with an estimated $20 \%$ of those initially approached remaining in the sample at the 2-year follow-up (of whom an even smaller percentage were widowers). Furthermore, although rates were compared with rates for nonbereaved groups and with distress rates while the spouses were still alive, it must be noted that, at all times, all of the study participants were facing a life-threatening situation; thus, it would be expected that the distress "baseline" would be high. However, it is indeed possible that the widow excess that emerged only after 2 years indicates a longer term reversal; that is, widows in this sample were relatively more poorly adjusted than widowers in the longer term (which, as noted earlier, is not the central interest of this article).

Finally, on the basis of data derived from a large-scale, nationally representative longitudinal study of 13,008 noninstitutionalized adults in the United States, Marks and Lambert (1998) found that becoming widowed between the two points of measurement was associated with marginally greater increases in symptoms of depression among women than men $(p<.10)$. The problem with this finding, which runs against the results of all of the other methodologically strong studies described earlier, is that it was based on only 10 widowers (as compared with 82 widows).

In conclusion, there is no large and unequivocal body of research confirming the pattern of relative widower excesses in levels and rates of depression observed nearly two decades ago (M. Stroebe \& Stroebe, 1983). Nevertheless, the large-scale, methodologically more sophisticated studies of Umberson et al. (1992), Siegel 
and Kuykendall (1990), and Cramer (1993) provide substantial evidence in favor of widower excesses and support the conclusions from earlier studies conducted by Glick et al. (1974) and Radloff (1975). Studies making claims to the contrary have typically failed to take into account such factors as baseline rates (relatively more widows and higher depression rates for women) and the potential selection factor. Further research is needed not only to confirm these conclusions but to establish subgroup patterns. In particular, patterns for different age groups are still unclear, for example, whether older widowers are at especially high risk, as could be inferred from the Gallagher et al. (1983) results. Also needed is further exploration of patterns across the duration of bereavement. Do the detrimental consequences for widowers really persist longer than the consequences for widows, as suggested by some but not all studies?

\section{Mental Illness}

It is evident that "mental illness," as a category, combines many diverse and unrelated disorders, and to treat all phenomena within a common framework has long been recognized as problematic (cf. Gove, 1980). However, because the interest here is in differences between widowed and married individuals in the rates of psychiatric problems severe enough to reach criteria for professional treatment, it seems justifiable to group together diverse psychiatric illnesses, disregarding for the moment differences in etiology or symptomatology. The emphasis here, unlike the previous section, is on diagnosed categories of mental disorders.

There is long-standing evidence that mental illness incidence rates are consistent with findings on various measures of distress and depression. Rates of mental illness are typically higher for widowed than married individuals and higher for women than men (Bebbington, 1987; Bloom, Asher, \& White, 1978; Fox, 1984; Parkes, 1964; Regier et al., 1988). In addition, the difference in mental health status between married and widowed individuals is greater for men than for women. A classic review of this literature was conducted by Gove (1972b), who identified the pattern just described very consistently across a variety of studies. On the basis of three early data sets used by Gove (1972b), Fox (1980) argued that female excesses are to be found across all marital status categories if data are analyzed in regard to untreated mental illnesses. Feinson (1986) concluded, on the basis of a study involving a cross-sectional design, that there were no gender differences in the prevalence of "mental disorders" (assessed with the Symptom Checklist 90; Derogatis, 1977) among a small sample (40 widowers and 119 widows) of bereaved elderly people. However, it was unclear whether Gender $\times$ Marital Status ratios were computed and, given the small sample, unlikely that they would be found. In contrast, Gove's findings have been confirmed in more recent, methodologically sounder surveys (e.g., Bebbington, 1987; Gove, Hughes, \& Style, 1983). Bebbington (1987) presented data from English national statistics for first admissions with affective disorders for the years 1982-1985. Although widowed men had lower absolute admission rates than widows, they were at higher relative risk. Bebbington (1987) concluded that, in terms of risk of affective disorder, being widowed makes more difference to a man than it does to a woman.

Analyses have recently been extended to comparisons between Black and White widowed men and women, revealing intriguing variations (study of the health consequences of bereavement among Black persons having been generally neglected in the past). It seems that, although the pattern of relative male excess in mental illness during bereavement is still a robust phenomenon for Whites, a different pattern may pertain for Black persons. Williams, Takeuchi, and Adair (1992) conducted a crosssectional survey of psychiatric disorders among both Whites and Blacks by marital status $(N=18,571)$. They found that widowed Black men and women, like their White counterparts, had higher rates of disorder than married individuals. In this survey, excesses for White widowed women (vs. married women) did not reach significance when adjustments were made for socioeconomic status and household size, whereas excesses did reach significance for widowed Black women. Gender ratios were calculated, that is, the rate of widowed to married men divided by the rate of widowed to married women. Opposite patterns of relative risk were found for Blacks and Whites with respect to these comparisons. Patterns for White widowers consistently indicated that widowhood was worse for them than for widows; among Blacks, 
widowhood was worse for widows than for widowers (apart from anxiety disorders).

How can this discrepancy in the gender difference pattern for Blacks versus Whites be explained? Williams et al. (1992) suggested an explanation in terms of differences in the social and psychological contexts of marital dissolution for Whites and Blacks. Whereas widowed White men experience great social isolation and loneliness, widowed Black men are likely to receive high levels of support from family and friendship networks. Thus, although this study provides confirmation of the relative excess that we identified previously (M. Stroebe \& Stroebe, 1983), it indicates that the pattern may indeed be culturally specific. Intriguing-and important--though this is potentially, it is advisable to wait for further empirical evidence before drawing general conclusions.

Some recent studies, including that by Williams et al. (1992) just described, have also provided diagnosis-specific information in the mental illness area by gender and marital status. There are indications from a number of studies that male excesses during bereavement may fall particularly excessively within the diagnostic category of alcoholic disorders, whereas bereaved women's mental illness patterns may rather be classified within depressive disorders (see W. Stroebe \& Stroebe, 1987). This would seem to be in accordance with gender differences in ways of coping (cf. de Ridder, 2000). Women express their emotionality, vent their distress, confide in others, and use formal resources (including psychotherapy), whereas men remain silent and keep feelings of distress and anxiety to themselves (though, nevertheless, as shown earlier, widowers do have relatively higher self-reported depression rates than widows). We discuss these issues in greater detail subsequently. It has in fact been shown that widowers have a higher alcohol intake than married men, but this is not the case for widows versus married women (Cramer, 1993; Williams et al., 1992), In this context, it is also interesting to note that emotional distress and alcohol use have recently been viewed as gender-linked responses to the same stressful experience, with men increasing alcohol intake but reporting less emotional distress during severe stress and women experiencing the opposite effects (Horwitz \& Davies, 1994).
In conclusion, information on mental illness derives from cross-sectional surveys and is thus subject to methodological shortcomings associated with this technique. In particular, more information is needed on patterns among the recently bereaved; in this case, large-scale surveys would be necessary, because the prevalence of mental disorders is low (e.g., as compared with undiagnosed depression rates). Recent evidence confirms the conclusion of early research that men may suffer relatively more from mental illness during widowhood than women. The findings may not extend to other cultural groups with different marital and social support patterns. Although some diagnosis-specific information is available, more studies to establish specific diagnoses in recently bereaved widows and widowers would be useful.

\section{Physical Symptoms and Illnesses}

Physical health detriments are frequent among recently bereaved persons, affecting both men and women (Parkes, 1996; W. Stroebe \& Stroebe, 1987). They not only suffer from a variety of physical symptoms and illnesses but have higher rates of disability than married individuals and exhibit increased use of medical services, such as consultations with doctors, consumption of prescribed medicines, and hospitalizations (Joung, van der Meer, \& Mackenbach, 1995; M. Morgan, 1980; Verbrugge, 1979). In addition to this pattern, a gender difference has been reported: Women suffer physical health problems and illnesses and use health services more than men (Verbrugge, 1989; Verbrugge \& Wingard, 1987). A number of processes have been suggested as explanations of this gender difference in morbidity, including the possibility that men are less willing to acknowledge or report symptoms than are women (see, e.g., Verbrugge, 1989; Wingard, 1984). This underlines the need, as described earlier, for within-gender comparisons of bereaved and nonbereaved individuals.

Glick et al. (1974), in their classic study of Boston widows and widowers, found higher scores on a specially constructed physical health questionnaire for widows than for widowers 14 months after bereavement, but only for the latter was there a significant difference in comparison with married controls. In other words, although absolute levels of symptomatology were higher 
among widows, relative excesses were greater for widowers. This pattern was similar to that of an early (less well-designed) study by Gerber and colleagues (Gerber, Rusalem, Hannon, Battin, \& Arkin, 1975; Gerber, Wiener, Battin, \& Arkin, 1975). However, Thompson, Breckenridge, Gallagher, and Peterson (1984), in the same study that failed to reveal differences between the genders on depression (discussed earlier), also found no Marital Status $\times$ Gender interactions on indexes of physical health among their sample of older widowed persons. Possibly the same reasons noted before to explain the negative results with respect to depression apply with respect to physical health as well. Also, Gallagher-Thompson et al. (1993), discussing this study, suggested the explanation that men are likely to underestimate their health problems during the early months of bereavement, because, indeed, they found gender differences in mortality (see subsequent discussion).

Joung et al. (1997; see also Joung, 1996) examined marital status differences in self-reported health in a prospective investigation of 3,510 men and women in the Netherlands. The usual pattern emerged, with widowed persons generally reporting poorer perceived health than married persons, although chronic conditions were not reported to be excessive. With respect to relative excesses, differences were apparent in perceived general health (widower-married ratio: 2.11; widow-married ratio: 1.05 ) and subjective health complaints (widowermarried ratio: 1.47; widow-married ratio: $0.83)$. This pattern suggests a relatively higher excess on self-reported health indexes for widowers than for widows. Similar results were reported in the study by Cramer (1993) reviewed earlier. Widowed and married persons' consultation rates for physical symptoms were assessed. There was a relatively greater excess for widowers than for widows.

That this pattern extends to indicators of disability (including limitations and assistance required for daily living and for work) was demonstrated in a recent study by Goldman, Korenman, and Weinstein (1995) using data from a longitudinal U.S. survey of aging and health. It was found that widowed men were at much higher risk of being disabled than married men, whereas the corresponding differential for women was considerably smaller.
In conclusion, the available evidence on physical health status of widows and widowers tends to support the patterns found for mental health reviewed earlier. The evidence so far shows widowers to be relatively more vulnerable than widows (i.e., as compared with their married counterparts) on physical health indexes ranging from self-reported health to chronic conditions, consultation rates, and disability. Surprisingly few studies are available. Methodologically sound investigations of the course of health among widowers and widows across the duration of their bereavement are urgently needed. Next, we turn to the body of evidence on the most extreme outcome of bereavement, namely mortality. With respect to this outcome, a more substantial literature has accumulated.

\section{Mortality}

Mortality patterns found in cross-sectional studies are quite consistent (Hu \& Goldman, 1990; M. Stroebe, Stroebe, Gergen, \& Gergen, 1981), and, with few exceptions, large-scale longitudinal studies have confirmed the pattern of relative widower excesses (Bowling \& Windsor, 1995; Helsing \& Szklo, 1981; Lillard \& Waite, 1995; Mellström, Nilsson, Oden, Rundgren, \& Svanborg, 1982; for a more detailed review, see M. Stroebe \& Stroebe, 1993). The overall picture is that mortality rates for widowers (vs. married men) are relatively higher than those for widows (vs. married women). As described subsequently (see also M. Stroebe et al., 1981; M. Stroebe \& Stroebe, 1993), there are discrepancies in a few studies for some subgroups (e.g., certain age groups or duration periods), and occasionally widows' rates have not been found significantly excessive in comparison with those of married women. However, in general, the mortality patterns provide the strongest evidence of all health indexes that widowers are indeed at relatively higher risk than widows, and, given that death is the most extreme consequence of bereavement, much weight may be attached to this finding.

Recent studies have become highly sophisticated in controlling for confounding variables and artifacts, and the relatively higher excess of widowers in comparison with widows has remained robust. Goldman et al. (1995) included extensive baseline controls (total baseline sam- 
ple: 7,500 ) and still found widowers to have higher odds of dying (by about $25 \%$ ) than married men. They concluded that the same may be true for widows, but the coefficients for women were smaller, and the estimated effects were insignificant. Similarly, in a recent survey (total sample: 36,142) incorporating control for income (which varied between the gender subgroups), Rogers (1995) found that being conjugally bereaved was much more detrimental for men than for women. Using data from their large prospective cohort study in the Netherlands, Joung, van de Mheen, Stronks, van Poppel, and Mackenbach (1998; see also Joung, 1996) successively adjusted for sociodemographic confounders and selection factors, health behaviors, and material circumstances in calculating relative mortality risks by marital status. Examination of this data set $(N=$ $27,000)$ showed consistently higher relative risk ratios for widowers than for widows (vs. their married counterparts). Finally, in a prospective study of mortality in Finland among all 35-84 year-old married persons, Martikainen and Valkonen (1996) found higher excess mortality for widowers $(17 \%)$ than for widows $(6 \%)$ even after controlling for confounding factors (e.g., homogamy, common accidents, and common unfavorable environments).

In line with these general patterns, dropout through mortality was significantly more excessive for widowers than for widows (same-gender nonbereaved controls were included) over the course of the longitudinal study conducted by Gallagher-Thompson and her colleagues (Gallagher-Thompson et al., 1993). This result is remarkable, given the small sample size for the identification of mortality differences. These investigators were able to identify social isolation and interpersonal difficulties as characterizing the decedents rather than the survivors in the study.

The duration of excessive mortality risk may also be longer for widowers than for widows. In a well-controlled, large-scale cohort study $(N=$ 12,522 spouse pairs), Schaefer, Quesenberry, and Soora (1995) found excessive relative risks for both bereaved men and women in the first year of loss (particularly the second half of this year). However, whereas the effects among women appeared to be limited to this period (after adjustment for other predictors of mortality) the risk of mortality among men, though decreasing somewhat after 2 years, still remained elevated over the subsequent years following bereavement. Similar results were reported in the Goldman et al. (1995) study. The increased mortality risks of widowhood among men were not concentrated in the early durations of widowhood, suggesting to the researchers that widowhood is a state of chronic rather than acute stress for widowers. This is contrary to the main body of research, including studies reviewed here, which has established most extreme effects early on.

Information is accumulating on causes of death that may account for the relatively higher mortality excess of widowers (see Mergenhagen, Lee, \& Gove, 1985; Rogers, 1995; M. Stroebe \& Stroebe, 1993). In an early crosssectional survey, Gove (1972a) found greater suicide (as well as attempted suicide) excesses for widowers relative to married men than for widows relative to married women. Longitudinal studies of the distribution of suicides over the duration of bereavement indicate that widowers are more at risk during the first few months, whereas the risk for widows spreads more evenly over a longer period (Bojanowsky \& Bojanowsky, 1976; MacMahon \& Pugh, 1965).

In a recent report, $\mathrm{Li}$ (1995) provided a detailed examination of the relative risk of suicide among widowed elderly people. $\mathrm{Li}$ included a large cohort of White married $(n=6,266)$ and widowed $(n=3,486)$ persons and conducted a 12-year follow-up survey. Adjustments were made in this study for housing, education level, age, church attendance, and smoking. The risk of suicide for widowers was more than five times that for married men, whereas the relative risk of suicide for widows was near unity. Information has also recently been collected on gender differences in bereavement across the broad spectrum of causes of death (e.g., Joung, Glerum, van Poppel, Kardaun, \& Mackenbach, 1996). Among widowers, $32.1 \%$ of excess mortality was due to diseases of the circulatory system, whereas, among widows, the percentage was only $21.7 \%$. Malignant tumors accounted for $22.3 \%$ of widows' excess mortality, whereas this cause was listed for only $13.5 \%$ of the excess of widowers. Other causes were roughly equivalent across the genders. In the survey by Rogers (1995) mentioned earlier, the exceptionally high mortality of widowers was 
found to be attributable to all causes, but particularly to those causes associated with social pathology, such as accidents, suicide, and cirrhosis of the liver.

Ethnic group comparisons in mortality among widowed individuals have also recently been made. We noted earlier a reversal in relative excess among Black men and women, the latter having relatively higher rates of psychiatric disorders than the former (Williams et al., 1992). It is interesting to note that, in a recent longitudinal study of mortality risk $(N=$ 11,112), Lillard and Waite (1995) found that Black men and women faced risks of dying approximately equal to those faced by their White counterparts when controls were made for potentially confounding variables such as income differences. Both Black and White widowers had relatively higher risks of dying than Black or White widows, as compared with their married counterparts. Why there should be a relatively higher excess for Black widowed women than for Black widowed men with respect to psychiatric disorders but not mortality remains to be clarified.

Negative results (of which there are few) have typically been reported for studies with very small samples (e.g., Rees \& Lutkins, 1967; Ward, 1976). Relatively large samples are necessary for significant differences in mortality to emerge. This can be illustrated with the study of Young, Benjamin, and Wallis (1963), in which 214 of the 4,486 widowers died during the first half year of bereavement, 66 more than would have been expected on the basis of a comparable married sample. This reflects a mortality rate of $4.8 \%$ for the widowed as compared with $3.2 \%$ for the married. If one were to study a hundred such widowers, one could not expect to find significant differences. For example, Jagger and Sutton (1991) reported a significantly elevated risk of mortality among a group of 161 elderly widows in the first 7 years of bereavement, but among the 41 widowers that could be followed, the increased relative risk did not reach an acceptable level of significance. Another recent study revealed a relatively higher risk for 76 young-old widows between 65 and 74 years of age than for 45 young-old widowers and 56 old-old widowers (Mendes de Leon, Kasl, \& Jacobs, 1993). Although the authors described this as a "threefold increase" in mortality risk during the 1st year of bereavement, it was accounted for by only 8 individuals. Thus, this result may not be reliable. Furthermore, it was found that old-old widows had a lower than expected mortality risk (only one death in the first 6 months of bereavement). Finally, examination of the data indicates that, overall, widowers' rates were in fact relatively more excessive than those of widows. Thus, this study does not provide strong contradictory evidence.

In summary, the mortality patterns provide strong support for the claim that men suffer relatively more (in comparison with their samegender controls) from the consequences of widowhood than women. There have been more studies conducted, and the patterns are, for the most part, clear-cut.

\section{Conclusions}

Conjugal bereavement results in increased morbidity and mortality for men and women, with men being relatively more vulnerable to the health risks than women, particularly-the data have shown-during the period of acute grief. Although these conclusions have not been unanimously shared, discrepant conclusions are due, as we have argued, to methodological oversights such as the failure to base conclusions on within-gender comparisons or to consider selection effects. More longitudinal research would be useful, for example, to establish relative risks within and across the specific areas (e.g., depressive symptomatology and mental and physical illness) among recently bereaved widows and widowers (vs. their respective nonbereaved counterparts) and high-risk subgroups of both men and women. Nevertheless, the convergence of evidence across the various manifestations does allow confidence in our conclusion that there are, in fact, relative male versus female excesses among those suffering from acute grief.

\section{Theoretical Interpretation of Gender Differences in Health Consequences of Bereavement}

How can this pattern of relative male excesses in health detriments during bereavement be explained? In an earlier theoretical discussion (M. Stroebe \& Stroebe, 1983), it was ar- 
gued that gender differences in social support after bereavement offered the most plausible explanation. In the meantime, increasing evidence has emerged to indicate the necessity for an extension of this perspective to include analysis of gender differences in methods of coping with bereavement. In this section, we reevaluate the different determinants using cognitive stress theory as a heuristic framework.

The basic assumption of stress theory is that stressful life events play an important role in the etiology of various somatic and psychiatric disorders (see, e.g., Lazarus \& Folkman, 1984). More specifically, it is assumed that a stressful life event may precipitate the onset of a physical or mental disorder, particularly if a predisposition toward that disorder already exists. Furthermore, research has identified neurophysiological mechanisms linking stress with various detrimental consequences for the immune, gastrointestinal, and cardiovascular systems (see Baum \& Grunberg, 1991).

According to cognitive stress theory, critical life events such as bereavement are stressful because they require major readjustment (e.g., Lazarus \& Folkman, 1984; W. Stroebe \& Stroebe, 1987). The intensity of stress created by a life event depends on the extent to which the perceived demands of the situation are appraised by individuals as taxing or exceeding their coping resources, given that failure to cope leads to important negative consequences (Lazarus \& Folkman, 1984). Stress theory provides the theoretical underpinning for the socalled "buffering model," which suggests that high levels of social support protect individuals against the deleterious impact of stress on health.

When a situation has been appraised as stressful, individuals must do something to master the situation or to control their emotional reactions to the situation. Coping is a complex and multidimensional phenomenon encompassing a variety of strategies, skills, and behaviors (cf. Carpenter, 1992; de Ridder, 2000; Krohne, 1993). Two dimensions of coping have been identified as central within the general domain of stress-coping theory: emotion-focused versus problem-focused coping and confrontational versus avoidant strategies of coping (de Ridder, 1997). Emotion-focused coping "includes behavioral or cognitive responses whose primary function is to manage the emotional consequences of stressors and to help maintain one's emotional equilibrium" (Billings \& Moos, 1981 , p. 141). Problem-focused coping "includes attempts to modify or eliminate the sources of stress through one's own behavior" (Billings \& Moos, 1981, p. 141). It is important to note that emotion-focused and problemfocused coping are not regarded as mutually exclusive. The second dimension of coping has been identified through a variety of different formulations, including vigilance-cognitive avoidance (Krohne, 1993); monitoring-blunting (Miller, Combs, \& Kruus, 1993) and avoidant-non-avoidant coping (Suls \& Fletcher, 1985).

In the context of marital bereavement, gender differences could be predicted with respect to different aspects of the stress-coping equation outlined earlier. First, the demands of situations could be less stressful for women than for men (Dressler, 1985). Second, there could be gender differences in the way the situation is appraised. For example, women might appraise the consequences of partner loss as less stressful than men. Third, there could be gender differences in coping resources, particularly in social support, because men are likely to rely exclusively on their wives as confidants, whereas women frequently have confidants outside their marriage (cf. M. Stroebe \& Stroebe, 1983; Thoits, 1986). Finally, there could be differences in coping strategies between men and women (Barnett, Biener, \& Baruch, 1987; Belle, 1987; Hobfoll, Dunahoo, Ben-Porath, \& Monnier, 1994; Miller \& Kirsch, 1987).

\section{Situational Demands and Stress Appraisal}

Gender differences in situational demands have mainly been analyzed in the context of role theory (e.g., Bernard, 1972; Gove, 1972b, 1973). Role theorists have argued that, as a result of the greater advantages men have in marriage, the loss of a partner is more stressful for men than for women. It has also been suggested that there may be different stressors involved for men than for women. Umberson et al. (1992), in their study of bereaved spouses, found that, among widows, the primary mechanism causing depression appeared to be financial strain, whereas for widowers it seemed to be strains associated with household management. 
It is important to note, however, that the extent to which a situation is experienced as stressful is determined not by the objective characteristics of the situation but by processes of cognitive appraisal. Bereaved men and women may differ in their (primary) appraisal of a loss as harmful to their well-being. They may also differ in their (secondary) appraisal of their ability to cope with their loss. Although there have been few studies on gender differences in appraisal of stressful situations, the evidence that is available suggests that women, relative to men, exhibit higher ratings of how "upsetting" an event is or how much adjustment would be required (Bradley, 1980; de Ridder, 2000; Sigmon, Stanton, \& Snyder, 1995). It is less clear, however, whether their higher reactivity to stressful situations results in less adequate coping. In her extensive review of gender differences in stress and coping, de Ridder (2000) suggested that the higher reactivity of women may by a disadvantage mainly when transient stressors are involved, but may be useful in coping with more chronic stressors. Given that bereavement has a long-term impact, this would suggest an advantage for women relative to men.

\section{Resources: Social Support and Buffering}

Wives have been identified as their husbands' main and sometimes only confidants, whereas women are more likely to have someone in addition to their husband in whom to confide and turn to: notably, another woman (cf. Belle, 1987; Fischer \& Phillips, 1982; Lin \& Westcott, 1991; Umberson et al., 1992). Thus, women are more likely to have close relationships with persons other than their spouses and to be the ones to nurture and sustain the couple's social relationships with others (Belle, 1987; Thoits, 1986, 1991). These differential patterns are likely to be operant in adjustment to bereavement: It has been suggested that widows generally receive more social support than widowers and that their higher level of social support protects or buffers them against the deleterious effect of partner loss (L. A. Morgan, 1984).

Research on the role of social support in adjustment to loss has focused exclusively on testing the buffering model against the main effect model. The results of these studies have been inconsistent. Although some have indeed reported evidence of buffering (Krause, 1986; Norris \& Murrell, 1990; Schwarzer, 1992), albeit using measures of social integration or received social support, others have not (Greene \& Feld, 1989; Murphy, 1988; W. Stroebe, Stroebe, Abakoumkin, \& Schut, 1996). The role of social support in accounting for gender differences in bereavement outcomes has received minimal research attention. There are two parts to this hypothesis, namely (a) that there are gender differences in the levels of social support perceived or received by widowed individuals and (b) that these differential levels of social support are responsible for gender differences in health outcomes. There is some evidencemainly from studies of the elderly-that widows receive more social support than widowers (e.g., Berardo, 1970; Bock \& Webber, 1972; Perlman, Gerson, \& Spinner, 1978); however, before an analysis conducted as part of the Tübingen Longitudinal Study of Bereavement, it had never been tested empirically whether differential social support is, in fact, responsible for gender differences in bereavement outcomes.

In the course of the latter study (e.g., W. Stroebe, Stroebe, \& Abakoumkin, 1999; W. Stroebe et al., 1988, 1996), data were collected that allowed a test of these hypotheses. In this study, 30 widows and 30 widowers were assessed after their loss experiences, and their levels of perceived social support as well as depressive symptomatology were repeatedly measured over a 2-year period. These measurements were then compared with the same set of measurements collected with a matched sample of married controls. Although there was some evidence that widows received more social support than widowers, there was no indication that this gender difference was responsible for gender differences in bereavement outcomes (W. Stroebe et al., 1999). This failure to find confirmation for the stress-theoretical hypothesis that social support is responsible for gender differences in bereavement outcomes is consistent with attachment theory, which rejects the notion that supportive friends can compensate for the loss of an attachment figure (Bowlby, 1969; Weiss, 1975; see also W. Stroebe et al., 1996). Thus, even though it would be premature on the basis of one study to rule out social support as a factor contributing to gender differences in bereavement outcome, it has to be 
acknowledged that there is little empirical support for this interpretation.

\section{Coping Styles}

In the last decade, differences in coping styles have become a major focus of research. Applied to gender differences in the health consequences of bereavement, an interpretation in terms of coping would be based on two assumptions: (a) that there are gender differences in coping with bereavement and (b) that the strategies used by women are more effective than those used by men.

\section{General Patterns of Coping}

A substantial number of studies have revealed that men tend, on the whole, to use more problem-focused coping than women, whereas women are more likely to use emotion-focused coping strategies (e.g., Billings \& Moos, 1981; de Ridder, 2000; Endler \& Parker, 1990; Folkman \& Lazarus, 1980; Pearlin \& Schooler, 1978; Ptacek, Smith, \& Zanas, 1992; Stone \& Neale, 1984; Vingerhoets \& van Heck, 1990). Conclusions are not completely unanimous, however: In one study involving a student sample, differences between the genders were not found on emotion- and problem-focused coping (Thoits, 1991).

It has been claimed that, in general, problemfocused strategies are more effective than emotion-focused ones (Billings \& Moos, 1984; Hobfoll et al., 1994; Hovanitz \& Kozora, 1990), which-if we accept the gender difference pattern found in the majority of studies-would imply better functioning (and consequences) among men than among women. Other studies have indicated, however, that the effectiveness of problem- versus emotion-focused strategies is dependent on the particular stressor or stressful situation; for example, problem-focused coping is less useful if the situation is uncontrollable (see de Ridder, 2000; Folkman, 1992).

With respect to the confrontation-avoidance dimension, there is some agreement that men are more avoidant in coping with stressors than are women (de Ridder, 2000; Krohne, 1993). For example, men are more likely to engage in distracting behavior (avoidance coping) when depressed, whereas women are more likely to ruminate (Nolen-Hoeksema, Parker, \& Larson,
1994); also, as noted earlier, women are more likely to confide their troubles to others and to be more expressive of their emotions (e.g., Derlega et al., 1993).

It has further been argued that the effectiveness of confrontive versus avoidant strategies varies according to the nature of the stressor, its controllability, and the duration of coping efforts required in dealing with it (Suls \& Fletcher, 1985; Weidner \& Collins, 1993). When the particular stressor of bereavement is considered, it becomes evident that the distinctions made between problem- and emotion-focused coping, avoidant and confrontive strategies, and the controllable versus uncontrollable nature of a stressor need more detailed, precise specification.

\section{Implications for Coping With Bereavement}

Although many of the stressful consequences of partner loss (e.g., financial strain or problems in household management) that aggravate the distress resulting from bereavement are amenable to problem-focused coping, the most fundamental source of stress in bereavementnamely, grief over the loss of a loved personcannot be changed in the sense that separation from the deceased cannot be reversed. As noted earlier, unchangeable, uncontrollable situations are said to be better dealt with through emotionfocused coping. However, to cope in an emotion-focused way entails anything from wishful thinking to rumination, seeking information, venting emotions, suppressing or denying negative or positive emotions, engaging in pleasant activities, and engaging in dangerous activities (e.g., drinking alcohol). It is evident that not all of these emotion-focused strategies would be predictors of good adjustment to bereavement, and (as described shortly), for some, the opposite prediction has been substantiated (e.g., for rumination).

A more limited construct than emotionfocused coping that has become familiar within the field of bereavement research is the notion of "working through" grief. Although subject to criticism, this has been a central concept in traditional grief theories (for reviews, see $M$. Stroebe, 1992; M. Stroebe \& Stroebe, 1991; Wortman \& Silver, 1987, 1989). According to the so-called grief work hypothesis, which de- 
rives from psychoanalytic theory and attachment theory (Bowlby, 1980; Freud, 1917/1957; Lindemann, 1944), one needs to work though grief and confront the reality of loss, and not to do so is unhealthy. This, then, incorporates a confrontation-avoidance coping dimension. This notion is also consistent with a body of research conducted by Pennebaker and his colleagues (e.g., Pennebaker, 1990; Pennebaker \& O'Heeron, 1984; Traue \& Pennebaker, 1992) that has consistently shown the benefits of disclosing emotions, including those relating to bereavement (note, however, recent reviews by Kelly \& McKillop, 1996, and Zech, 2000, arguing that disclosure may not always be beneficial, and positive effects may be a function of the type or manner of disclosure and the receptivity of the social environment).

\section{Do Gender Differences in Coping With Bereavement Mediate the Differential Health Pattern?}

The prediction from the preceding discussion would be that confronting one's grief, as followed by women, would be more effective than avoiding it, as preferred by men. This would be in favor of women's way of coping with stress in general and could, if valid, explain gender differences in bereavement outcomes. Women cope better and have fewer health consequences because they confront and express their grief more than men.

Gender differences in coping with bereavement. There are very few studies that have directly addressed the topic of how widows and widowers go about their grieving and what impact this has on outcomes. Thus, we cannot say to what extent the patterns of gender differences in coping with stressful events in general (reviewed earlier) apply specifically to bereavement. However, some indications can be derived from research on related issues. Results from the Tübingen Longitudinal Study of Bereavement showed gender differences in willingness to communicate that were related to depressive symptomatology (M. Stroebe \& Stroebe, 1989, 1991). There was a disinclination among widowers who were highly distressed to participate in interviews, whereas the opposite was the case for widows, for whom interview participation was associated with greater distress than was refusal to participate
(M. Stroebe \& Stroebe, 1989). It seemed that the widowers avoided the opportunity to share their deep emotions, whereas, for widows, the interviews provided an opportunity to talk about their feelings with a sympathetic other. This interpretation was supported by additional findings on "talking to others" (widows also talked more about their loss; M. Stroebe et al., 1993).

Differential effectiveness of coping styles. There was also evidence that individuals who talked about their loss had fewer depressive and somatic symptoms and were in better health than those who did not talk about their loss. However, this relationship is correlational and thus not necessarily indicative of a causal role of talking about grief in reducing depressive symptomatology. It could simply be that those with higher symptomatology need to communicate more (i.e., the opposite direction of causality). Further analyses showed no evidence that confiding in others actually reduced symptomatology over time. Similarly, in an investigation conducted in the Netherlands, there was no indication that the social sharing of emotions, whether defined as confiding or more widely in the sense of allowing others to see one's emotions, had any beneficial impact on symptom levels (Schut, 1992; Schut, Stroebe, Stroebe, van den Bout, \& de Keijser, 1994; M. Stroebe et al., 1993).

One shortcoming of the preceding analysis is that it assesses only overt strategies of coping. It is possible to confront emotions and "do one's grief work" in other ways, many of them intrapersonal. Further analyses of the impact across time of adopting confrontational versus nonconfrontational coping strategies showed that widowers who avoided grief work were more depressed later in the study than widowers who confronted their grief. For widows, the style adopted seemed to make little difference (M. Stroebe \& Stroebe, 1991). Thus, there was only limited support for the notion that working through grief fosters adjustment. A potential explanation is that men who distract do so more completely and to the detriment of their health - they, in fact, do need to confront their emotions somewhat more-whereas women, as a result of the context in which they grieve and their more open grieving style, typically have more occasion to work through grief. On the other hand, women will be prevented, by household and family tasks, from exclusively engag- 
ing in their preferred style of emotion-focused coping.

\section{Coping With Bereavement: A Reevaluation}

The findings just described raise doubts about the basic assumption underlying the grief work hypothesis that confronting one's grief is more effective than avoiding it (M. Stroebe, 1992). On the other hand, too complete an avoidance of grief also may not be conducive to recovery. What is suggested by these results is the need for a nonlinear model of recovery: Too much or too little grieving is maladaptive. Recent studies have begun to confirm this suggestion. NolenHoeksema et al. (1994) reported disadvantages of ruminating about bereavement. Rumination was defined in terms of concentration on depressive thoughts and their meaning and passive worrying. People with a ruminative style early in bereavement were found to have higher depression levels at 6 months (depression level at Time 1 was controlled). Those with a more distractive style became less depressed over time. Bereaved women were found to ruminate more than bereaved men. Compatible with this general pattern, in a study also focusing on bereavement (though not on gender differences), Bonanno, Keltner, Holen, and Horowitz (1995) provided evidence that avoidant strategies may be more functional than had previously been assumed in the bereavement literature.

To understand gender differences in bereavement, reexamination not only of the nature of the stressor, but also of processes of coping and of the efficacy of different strategies of coping, would seem necessary. M. Stroebe and Schut $(1995,1999)$ suggested a framework for conceptualizing these components in their dualprocess model of coping with loss, which is an adaptation of cognitive stress theory to the bereavement situation.

The model postulates that dealing with both the direct emotional consequences of loss and concurrently occurring life changes is essential for adjustment to loss and that preoccupation with one of these aspects, to the neglect of the other, slows down this process. They argued that the loss of a partner results in two sources of stress: (a) stress directly associated with the loss of the loved person and (b) stress that comes about as a secondary consequence of loss (namely, the changes in life that occur because the deceased is no longer present, such as role and identity changes). Thus, they proposed an orthogonal dimension of coping with loss. The dimension, designated loss-restoration orientation, ranges from the orientation toward the loss of an attachment figure to an orientation toward the secondary stresses due to the loss. It is evident, following the discussion in the previous section, that loss orientation is not equivalent to emotion-focused coping and that restoration orientation is not equivalent to problem-focused coping. To illustrate, restorationoriented coping differs from problem-focused coping in that it also subsumes emotion-focused coping associated with secondary stress management (one has fears about mastering the skills lost with the deceased, which could be tackled either by trying out the task or by working on one's fears).

Individuals who confront their loss would be engaging in grief work, or ruminating, or indulging in wishful thinking, whereas those who avoid it would not. Individuals could also differ in the extent to which they confront or avoid the secondary stresses associated with bereavement (e.g., the skills to be mastered may or may not be attempted). According to this perspective, there are both benefits and costs involved with confronting and avoiding grief, just as there are benefits and costs involved with tackling versus ignoring all of the additional tasks that arise as the result of loss.

A central component of the model that distinguishes it from classic stress-coping theory is a dynamic process fundamental to successful coping, namely, "oscillation" (for a discussion of the difference between this concept and that of "intrusion-avoidance" in the trauma literature, see M. Stroebe, Schut, \& Stroebe, 1998). This refers to the alternation between loss-oriented and restoration-oriented coping. At times, bereaved individuals will be confronted by their loss; at other times, they will avoid memories, be distracted, or seek relief by concentrating on other things, or there may simply be no alternative but to attend to the additional stressors (e.g., managing household chores or earning a living). The model proposes that oscillation is necessary for optimal adjustment over time (see the work of Helgeson [e.g., 1994; Helgeson \& Fritz, 1998] identifying the poor health consequences of unmitigated communion, a trait as- 
sociated with femininity, or unmitigated agency, associated with masculinity). Direct empirical investigation of this proposition is still needed.

The major prediction suggested by the dualprocess model is that both forms of coping are essential for effective coping. Thus, confrontation of a loss (i.e., including grief work) is essential for a healthy recovery, and this comes easily to women. However, if it is also relentless (no oscillation), no progress toward recovery is made; it is necessary to attend to other things as well. As noted earlier, this, however, is demanded of women who have the caring role and must attend to the household and to other tasks. It is our contention that men can more easily and completely block their emotions (being also generally more avoidant in their coping style) and not attend to the tasks defined in grief work by adopting a fairly exclusive restoration-oriented approach. We suggest that it is this difference in role constraints of men and women that is a major cause of gender differences in health outcomes of bereavement. In line with this argument, research has shown that men and women have different problems to cope with (cf. de Ridder, 2000; Folkman \& Lazarus, 1980; Porter \& Stone, 1995), men reporting more work-related problems and more miscellaneous problems and women reporting more problems focused on the self, parenting problems, and problems with other people (Porter \& Stone, 1995). In other words, differences between the genders may be due to the nature of the stressor in addition to differences in appraisal and coping.

Indirect support for the preceding interpretation of gender differences in bereavement outcome comes from the study of Schut (1992; Schut, Stroebe, van den Bout, \& de Keijser, 1997). This study offered grief counseling to widows and widowers for mildly disturbed grief. The participants had been bereaved for some time (ranging from 11 to 18 months after their loss). The program guided these men and women in their use of confrontive versus avoidant strategies in coping not only with the emotional aspects of bereavement but also with the secondary stressors with which they had difficulty. "Teaching" bereaved men and women to cope in the way that the opposite gender usually copes (teaching men to be more emotion oriented and women to be more problem oriented) was associated with a lowering of dis- tress. It seems plausible that what was achieved in intervention was assistance with confronting emotions for men and dealing with the secondary stressors of bereavement (or perhaps overfocus on emotions) for women. In each case, there were health benefits.

The argument can be summarized as follows: Grief over the loss of a loved person is the fundamental source of stress in bereavement, and if this loss is not processed, health deficits occur. Widows confront the emotional impact of their bereavement, which is advantageous for them; in doing so, however, they may tend to neglect confrontation with the variety of secondary stressors that are integral to bereavement. Men are more avoidant of the emotional impact of loss, focusing instead on dealing with secondary problems that arise through loss. For a healthy outcome, attention-avoidance of both stressor types is essential. Following this line of argument, gender differences in health outcomes of bereavement would be due to the fact that role constraints are more likely to prevent women than men from engaging exclusively in their preferred way of coping.

According to this model, the gender difference to be expected in the acute grieving phase would diminish, or even reverse, across the longer duration of bereavement. In the course of time, restoration orientation becomes more central, and this is easier for men. The disadvantages for widowers that have been identified here may become more advantageous as time goes on. There is some support for the assumption that, after intense reactions to loss have abated, widowers' lifestyles and situations, roles, and ways of coping may become as adaptive as, or even more adaptive than, widows' (cf. Hansson \& Carpenter, 1994; Hays et al., 1994; Nieboer et al., 1998; Stevens, 1995). However, we have also drawn attention to studies that appear to be less supportive of this pattern (e.g., Glick et al., 1974; Van Grootheest et al., 1999). Just as the central parameters of the model need further testing, so too do predictions such as these, about gender differences in the short and long term.

\section{Conclusion}

As indicated by the review of empirical studies on the morbidity and mortality of conjugal bereavement presented in the first part of this 
article, there is now a reasonably sound body of evidence to support the conclusion that men suffer relatively higher consequences of partner loss than do women. It is much less clear, however, how to interpret this pattern. The assumption made in an earlier review (M. Stroebe \& Stroebe, 1983) that gender differences in the social support received by widows and widowers were responsible for differential bereavement outcomes has not, in the meantime, received strong empirical support. Although the evidence as to the existence of such gender differences in social support after bereavement is quite persuasive, it has not been demonstrated that these differences mediate gender differences in health outcomes.

Although there is some support for the assumption that women are more likely to confront their emotions than men, there is little evidence that this type of confrontive coping, in itself, confers a health advantage. Therefore, we argued for a revision of the so-called grief work hypothesis and suggested the following assumptions: (a) that both coping orientations, those directed toward the tasks of loss and of restoration, are essential in coming to terms with the loss of a loved one; (b) that attention to and avoidance of both the direct emotional impact of loss itself and its secondary consequences are necessary (the oscillation process); and (c) that gender differences in bereavement outcomes are due to the fact that external constraints prevent women but not men from exclusively engaging in their preferred style of coping.

The "who suffers more" issue is still a complex one. Interpreted in terms of relative extremity of reactions to the loss or "relative risk" (in which case nonbereaved control groups or prebereavement data must be included in the analysis), research has clearly demonstrated that widowers suffer more than widows. However, if one is only interested in levels of distress among the bereaved (i.e., absolute risk), comparing rates of distress of widows and widowers directly without reference to nonbereaved controls, then the conclusion would be that men and women suffer to the same extent (or that suffering would be more pronounced for women). Finally, from a population perspective, the fact that there are many more widows than widowers means that there are more depressed widows than widowers. All of these conclusions are, then, correct. The confusion enters when absolute risks are interpreted as relative risks. If one is interested in the impact of bereavement on levels of distress among men and women, as we were in this analysis, then only one conclusion is correct: Men suffer more.

\section{References}

Barnett, R. C., Biener, L., \& Baruch, G. K. (Eds.). (1987). Gender and stress. New York: Free Press.

Baum, A., \& Grunberg, N. E. (1991). Gender, stress and health. Health Psychology, 10, 80-85.

Bebbington, P. (1987). Marital status and depression: A study of English national admission statistics. Acta Psychiatrica Scandinavica, 75, 640-650.

Beck, A. T. (1967). Depression: Clinical, experimental and theoretical aspects. New York: Hoeber.

Belle, D. (1987). Gender differences in the social moderators of stress. In R. C. Barnett, L. Biener, \& G. K. Baruch (Eds.), Gender and stress (pp. 257277). New York: Free Press.

Berardo, F. M. (1970). Survivorship and social isolation: The case of the aged widower. Family Coordinator, 19, 11-25.

Bernard, J. (1972). The future of marriage. Harmondsworth, Middlesex, England: Penguin Books.

Bierhals, A., Frank, E., Prigerson, H., Miller, M., Fasiczka, A., \& Reynolds, C. (1996). Gender differences in complicated grief among the elderly. Omega: Journal of Death and Dying, 32, 303-317.

Billings, A. G., \& Moos, R. H. (1981). The role of coping responses and social resources in attenuating the stress of life events. Journal of Behavioral Medicine, 4, 139-157.

Billings, A. G., \& Moos, R. H. (1984). Coping, stress, and social resources among adults with unipolar depression. Joumal of Personality and Social Psychology, 46, 877-891.

Bloom, B. L., Asher, S. J., \& White, S. W. (1978). Marital disruption as a stressor: $A$ review and analysis. Psychological Bulletin, 85, 867-894.

Bock, E. W., \& Webber, I. L. (1972). Suicide among the elderly: Isolating widowhood and mitigating alternatives. Journal of Marriage and the Family, 34, 24-31.

Bojanowsky, J., \& Bojanowsky, A. (1976). Zur Risikozeit des Selbstmordes bei Geschiedenen und Verwitweten [Period of risk for suicides among the divorced and widowed]. Nervenarzt, 47, 307-309.

Bonanno, G. A., Keltner, D., Holen, A., \& Horowitz, M. J. (1995). When avoiding unpleasant emotions may not be such a bad thing: Verbal-autonomic response dissociation and midlife conjugal bereavement. Journal of Personality and Social Psychology, 69, 975-989. 
Bornstein, P. E., Clayton, P. J., Halikas, J. A., Maurice, W. L., \& Robbins, E. (1973). The depression of widowhood after thirteen months. British Journal of Psychiatry, 122, 561-566.

Bowlby, J. (1969). Attachment and loss: Vol. 1. Attachment. New York: Basic Books.

Bowlby, J. (1980). Attachment and loss: Vol. 3. Loss: Sadness and depression. New York: Basic Books.

Bowling, A., \& Windsor, J. (1995). Death after widowhood: An analysis of mortality rates up to 13 years after bereavement. Omega: Journal of Death and Dying, 31, 35-39.

Bradley, C. (1980). Gender differences in reporting and rating of life events: A comparison of diabetic and healthy subjects. Journal of Psychosomatic Research, 24, 35-37.

Carey, R. G. (1977). The widowed: A year later. Journal of Counseling Psychology, 24, 125-131.

Carey, R. G. (1979). Weathering widowhood: Problems and adjustment of the widowed during the first year. Omega: Journal of Death and Dying, 10, 163-174.

Carpenter, B. N. (Ed.). (1992). Personal coping: Theory, research, and application. Westport, CT: Praeger.

Carter, H., \& Glick, P. C. (1976). Marriage and divorce: A social and economic study. Cambridge, MA: Harvard University Press.

Chen, J. H., Bierhals, A. J., Prigerson, H. G., Kasl, S. V., Mazure, C. M., \& Jacobs, S. (1999). Gender differences in the effects of bereavement-related psychological distress in health outcomes. Psychological Medicine, 29, 367-380.

Clayton, P. J. (1990). Bereavement and depression. Journal of Clinical Psychiatry, 51, 34-40.

Clayton, P. J., Halikas, J. A., \& Maurice, W. L. (1972). The depression of widowhood. British Journal of Psychiatry, 120, 71-76.

Cramer, D. (1993). Living alone, marital status, gender and health. Journal of Applied and Community Social Psychology, 3, 1-15.

de Ridder, D. (2000). Gender, stress and coping: Do women handle stressful situations differently from men? In L. Sherr \& J. S. St. Lawrence (Eds.), Women, health and the mind (pp. 115-135). Chichester, England: Wiley.

de Ridder, D. (1997). What is wrong with coping assessment? A review of conceptual and methodological issues. Psychology and Health, 12, 417431.

Derlega, V. J., Metts, S., Petronio, S., \& Margulis, S. T. (1993). Self-disclosure. Newbury Park, CA: Sage.

Derogatis, L. R. (1977). SCL-90: Administration, scoring and procedures manual for the revised version. Baltimore: John Hopkins University Press.
Dressler, W. W. (1985). The social and cultural contexts of coping: Action, gender and symptoms in a southern Black community. Social Science and Medicine, 21, 499-506.

Endler, N. S., \& Parker, J. D. A. (1990). Multidimensional assessment of coping: A critical evaluation. Journal of Personality and Social Psychology, 58, 844-854.

Faschingbauer, T. R., Zisook, S., \& DeVaul, R. (1987). The Texas Revised Inventory of Grief. In S. Zisook ((Ed.), Biopsychsocial aspects of grief and bereavement (pp. 109-124). Washington, DC: American Psychiatric Press.

Feinson, M. (1986). Aging widows and widowers: Are there mental health differences? International Journal of Aging and Human Development, 28, 251-260.

Fischer, C. S., \& Phillips, S. L. (1982). Who is alone: Social characteristics of people with small networks. In L. A. Peplau \& D. Perlman (Eds.), Loneliness: A sourcebook of current theory, research and therapy (pp. 21-33). New York: Wiley.

Folkman, S. (1992). Making the case for coping. In B. N. Carpenter (Ed.), Personal coping: Theory, research, and application (pp. 31-46). Westport, CT: Praeger.

Folkman, S., \& Lazarus, R. (1980). An analysis of coping in a middle-aged community sample. Journal of Health and Social Behavior, 2, 219-239.

Fox, J. W. (1980). Gove's specific gender-role theory of mental illness: A research note. Journal of Health and Social Behavior, 21, 260-267.

Fox, J. W. (1984). Gender, marital status, and age as social selection factors in recent psychiatric treatment. Journal of Health and Social Behavior, 25, 394-405.

Freud, S. (1957). Mourning and melancholia. In J. Strachey (Ed. and Trans.), Standard edition of the complete works of Sigmund Freud (pp. 243-258). London: Hogarth Press. (original work published 1917).

Gallagher, D. E., Breckenridge, J. N., Thompson, L. W., \& Peterson, J. A. (1983). Effects of bereavement on indicators of mental health in elderly widows and widowers. Journal of Gerontology, 38, 565-571.

Gallagher-Thompson, D., Futterman, A., Farberow, N., Thompson, L. W., \& Peterson, J. (1993). The impact of spousal bereavement on older widows and widowers. In M. Stroebe, W. Stroebe, \& R. O. Hansson (Eds.), Handbook of bereavement: Theory, research, and intervention (pp. 227-239) New York: Cambridge University Press.

Gerber, I., Rusalem, R., Hannon, N., Battin, D., \& Arkin, A. (1975). Anticipatory grief and aged widows and widowers. Journal of Gerontology, 30 , 225-229. 
Gerber, I., Wiener, A., Battin, D., \& Arkin, A. (1975). Brief therapy to the aged bereaved. In B. Schoenberg, A. C. Carter, A. H. Kutscher, D. Peretz, \& I. Goldberg (Eds.), Bereavement: Its psychosocial aspects (pp. 310-333). New York: Columbia University Press.

Gilbar, O., \& Dagan, A. (1995). Coping with loss: Differences between widows and widowers of deceased cancer patients. Omega: Journal of Death and Dying, 31, 207-220.

Glick, I., Weiss, R. S., \& Parkes, C. M. (1974). The first year of bereavement. New. York: Wiley.

Goldberg, D. P., \& Hillier, V. F. (1979). A scale version of the General Health Questionnaire. Psychological Medicine, 19, 139-145.

Goldman, N., Korenman, S., \& Weinstein, R. (1995). Marital status and health among the elderly. Social Science and Medicine, 40, 1717-1730.

Gove, W. R. (1972a). Gender, marital status, and suicide. Journal of Health and Social Behavior, 13, 204-213.

Gove, W. R. (1972b). The relationship between gender roles, marital roles, and mental illness. Social Forces, 51, 34-44.

Gove, W. R. (1973). Gender, marital status and mortality. American Journal of Sociology, 79, 45-67.

Gove, W. R. (1980). Mental illness and psychiatric treatment among women. Psychology of Women Quarterly, 4, 345-362.

Gove, W. R., Hughes, M., \& Style, C. (1983). Does marriage have positive effects on the psychological well-being of the individual? Journal of Health and Social Behavior, 24, 122-131.

Greene, R. W., \& Feld, S. (1989). Social support coverage and the well-being of elderly widows and married women. Journal of Family Issues, 10, $33-51$.

Hansson, R. O., \& Carpenter, B. N. (1994). Relationships in old age: Coping with the challenge of transition. New York: Guilford Press.

Hays, J. C., Kasl, S. V., \& Jacobs, S. C. (1994). The course of psychological distress following threatened and actual conjugal bereavement. Psychological Medicine, 24, 917-927.

Helgeson, V. S. (1994). Relation of agency and communion to well-being: Evidence and potential explanations. Psychological Bulletin, 116, 412-428.

Helgeson, V. S., \& Fritz, H. L. (1998). A theory of unmitigated communion. Personality and Social Psychology Review, 2, 173-183.

Helsing, K. J., \& Szklo, M. (1981). Mortality after bereavement. American Journal of Epidemiology, $114,41-52$.

Hobfoll, S. E., Dunahoo, C. L., Ben-Porath, Y., \& Monnier, J. (1994). Gender and coping: The dualaxis model of coping. American Journal of Community Psychology, 22, 49-82.
Horwitz, A. D., \& Davies, L. (1994). Are emotional distress and alcohol problems differential outcomes to stress? An exploratory test. Social Science Quarterly, 75, 607-621.

Hovanitz, C. A., \& Kozora, E. (1990). Life stress and clinically elevated MMPI scales: Gender differences in the moderating influence of coping. Journal of Clinical Psychology, 45, 766-777.

Hu, Y., \& Goldman, N. (1990). Mortality differentials by marital status: An international comparison. Demography, 27, 233-250.

Jacobs, S., Kasl, S. V., Ostfeld, A. M., Berkman, L., \& Charpentier, P. (1986). The measurement of grief: Age and gender variation. British Journal of Medical Psychology, 59, 305-310.

Jagger, C., \& Sutton, C. J. (1991). Death after marital bereavement: Is the risk increased? Statistics in Medicine, 46, 395-404.

Jeffery, R. W. (1989). Risk behaviors and health: Contrasting individual and population perspectives. American Psychologist, 44, 1194-1202.

Joung, I. (1996). Marital status and health: Descriptive and explanatory studies. The Hague: Koninklijke Bibliotheek.

Joung, I., Glerum, J. J., van Poppel, F. W., Kardaun, J. W., \& Mackenbach, J. P. (1996). The contribution of specific causes of death to mortality differences by marital status in the Netherlands. European Journal of Public Health, 6, 142-149.

Joung, I., Stronks, K., van de Mheen, H., van Poppel, F. W., van der Meer, J. B., \& Mackenbach, J. P. (1997). The contribution of intermediary factors to marital status differences in self-reported health. Journal of Marriage and Family, 59, 476-490.

Joung, I., van de Mheen, H., Stronks, K., van Poppel, F. W., \& Mackenbach, J. P. (1998). A longitudinal study of health selection in marital transitions. Social Science and Medicine, 46, 425-435.

Joung, I., van der Meer, J. B., \& Mackenbach, J. P. (1995). Marital status and health care utilization. International Joumal of Epidemiology, 24, 569575.

Kelly, A. E., \& McKillop, K. J. (1996). Consequences of revealing personal secrets. Psychological Bulletin, 120, 450-465.

Krause, N. (1986). Social support, stress, and wellbeing among older adults. Journal of Gerontology, 41, 512-519.

Krohne, H. W. (Ed.). (1993). Attention and avoidance. Seattle, WA: Hogrefe \& Huber.

Lazans, R. S., \& Folkman, S. (1984). Stress, appraisal, and coping. New York: Springer.

Lee, G. R., Willetts, M. C., \& Seccombe, K. (1998). Widowhood and depression: Gender differences. Research on Aging, 20, 611-630.

Li, G. (1995). The interaction effect of bereavement and gender on the risk of suicide in the elderly: An 
historical cohort study. Social Science and Medicine, 40, 825-828.

Lillard, L. A., \& Waite, L. J. (1995). 'Til death do us part: Marital disruption and mortality. American Journal of Sociology, 100, 131-156.

Lin, N., \& Westcott, J. (1991). Marital engagement/ disengagement, social networks, and mental health. In J. Eckenrode (Ed.), The social context of coping (pp. 213-237). New York: Plenum.

Lindemann, E. (1944). Symptomatology and management of acute grief. American Journal of Psychiatry, 101, 141-148.

Lund, D. A., Caserta, M. S., \& Dimond, M. F. (1986). Gender differences through two years of bereavement among the elderly. Gerontologist, 26, 314-320.

MacMahon, B., \& Pugh, T. F. (1965). Suicide in the widowed. American Journal of Epidemiology, 81, 23-32.

Marks, N. F., \& Lambert, J. D. (1998). Marital status continuity and change among young and midlife adults: Longitudinal effects on well-being. Journal of Family Issues, 19, 652-686.

Martikainen, P., \& Valkonen, T. (1996). Mortality after death of spouse in relation to duration of bereavement in Finland. Journal of Epidemiology and Community Health, 50, 264-268.

Mellström, D., Nilsson, A., Oden, A., Rundgren, A., \& Svanborg, A. (1982). Mortality among the widowed in Sweden. Scandinavian Journal of Social Medicine, 10, 33-41.

Mendes de Leon, C., Kasl, S. V., \& Jacobs, S. (1993). Widowhood and mortality risk in a community sample of the elderly: A prospective study. Journal of Clinical Epidemiology, 46, 519-527.

Mergenhagen, P. J., Lee, B. A., \& Gove, W. R. (1985). Till death us do part: Recent changes in the relationship between marital status and mortality. Sociology and Social Research, 70, 53-56.

Meshot, C. M., \& Leitner, L. M. (1993). Adolescent mourning and parental death. Omega: Journal of Death and Dying, 26, 287-299.

Miller, S. M., Combs, C., \& Kruus, L. (1993). Tuning in and tuning out: Confronting the effects of confrontation. In H. W. Krohne (Ed.), Attention and avoidance (pp. 51-69). Seattle, WA: Hogrefe \& Huber.

Miller, S. M., \& Kirsch, N. (1987). Gender differences in cognitive coping with stress. In R. C. Barnett, L. Biener, \& G. K. Baruch (Eds.), Gender and stress (pp. 278-307). New York: Free Press.

Morgan, L. A. (1984). Changes in family interaction following widowhood. Journal of Marriage and the Family, 46, 323-331.

Morgan, M. (1980). Marital status, health, illness and service use. Social Science and Medicine, 14A, $633-643$.
Murphy, S. A. (1988). Mental distress and recovery in a high-risk bereavement sample three years after untimely death. Nursing Research, 37, 30-35.

Nieboer, A. P., Lindenberg, S. M., \& Ormel, J. (1998). Conjugal bereavement and well-being of elderly men and women: A preliminary study. Omega: Journal of Death and Dying, 38, 113-142.

Nolen-Hoeksema, S., Parker, L. E., \& Larson, J. (1994). Ruminative coping with depressed mood following loss. Journal of Personality and Social Psychology, 67, 92-104.

Norris, F. H., \& Murrell, S. A. (1990). Social support, life events, and stress as modifiers of adjustment to bereavement by older adults. Psychology and $\mathrm{Ag}$ ing, 5, 429-436.

Notarious, C., \& Johnson, J. (1982). Emotional expression in husbands and wives. Journal of Marriage and the Family, 44, 483-489.

Osterweis, M., Solomon, F., \& Green, M. (1984). Bereavement: Reactions, consequences, and care. Washington, DC: National Academy Press.

Parkes, C. M. (1964). Recent bereavement as a cause of mental illness. British Journal of Psychiatry, $110,198-204$.

Parkes, C. M. (1996). Bereavement: Studies of grief in adult life (3rd ed.). New York: International Universities Press.

Pearlin, L., \& Schooler, C. (1978). The structure of coping. Journal of Health and Social Behavior, 19 , 2-21.

Pennebaker, J. W. (1990). Opening up: The healing power of confiding in others. New York: Morrow.

Pennebaker, J. W., \& O'Heeron, R. C. (1984). Confiding in others and illness rates among spouses of suicide and accidental death victims. Journal of Abnormal Psychology, 93, 473-476.

Pennebaker, J. W., \& Roberts, T. (1992). Toward a his and hers theory of emotion: Gender differences in visceral perception. Journal of Social and Clinical Psychology, 11, 199-212.

Perlman, D., Gerson, A. C., \& Spinner, B. (1978). Loneliness among senior citizens: An empirical report. Essence, 2, 239-248.

Porter, L. S., \& Stone, A. S. (1995). Are there really differences in coping? A reconsideration of previous data and results from a daily study. Journal of Social and Clinical Psychology, 14, 184-202.

Ptacek, J. T., Smith, R. E., \& Zanas, J. (1992). Gender, appraisal, and coping: A longitudinal analysis. Journal of Personality, 60, 747-770.

Radloff, L. (1975). Gender differences in depression: The effects of occupation and marital status. Gender Roles, 1, 249-265.

Radloff, L. S. (1977). The CES-D Scale: A selfreport depression scale for research in the general population. Applied Psychological Measure. ment, 1, 385-401. 
Rees, W., \& Lutkins, S. (1967). Mortality of bereavement. British Medical Journal, 4, 13-16.

Regier, D. A., Boyd, J. H., Burke, J. D., Rae, D. S., Myers, J. K., Kramer, M., Robins, L. N., George, L. K., Karno, M., \& Locke, B. Z. (1988). Onemonth prevalence of mental disorders in the United States. Archives of General Psychiatry, 45, 977-986.

Rogers, R. G. (1995). Marriage, gender, and mortality. Journal of Marriage and the Family, 57, 515 526.

Sanders, C. M., Mauger, P. A., \& Strong, P. A. (1991). A manual for the Grief Experience Inventory. Palo Alto, CA: Consulting Psychologists Press.

Schaefer, C., Quesenberry, C. P., \& Soora, W. (1995). Mortality following conjugal bereavement and the effects of a shared environment. American Journal of Epidemiology, 141, 1142-1152.

Schut, H. A. W. (1992). Omgaan met de dood van de partner: Effecten of gezondheid en effecten van rouwbegeleiding. [Coping with conjugal bereavement: Effects on psychological functioning and effects of grief counseling]. Amsterdam: Thesis Publishers.

Schut, H. A. W., Stroebe, M., Stroebe, W., van den Bout, J., \& de Keijser, M. A. (1994, June). Are accepted ways of coping with loss really efficacious? Paper presented at the Fourth International Conference on Grief and Bereavement in Contemporary Society, Stockholm, Sweden.

Schut, H. A. W., Stroebe, M., van den Bout, J., \& de Keijser, J. (1997). Gender differences in the efficacy of grief counseling. British Journal of Clinical Psychology, 36, 63-72.

Schwarzer, C. (1992). Bereavement, received social support, and anxiety in the elderly: A longitudinal analysis. Anxiety Research, 4, 287-298.

Shields, S. A. (1991). Gender in the psychology of emotion: A selective research review. In $\mathrm{K}$. $\mathrm{T}$. Strongman (Ed.), International review of studies on emotion (Vol. 1, pp. 227-245). Chichester, England: Wiley.

Siegel, J. M., \& Kuykendall, D. H. (1990). Loss, widowhood, and psychological distress among the elderly. Journal of Consulting and Clinical Psychology, 58, 519-524.

Sigmon, S. T., Stanton, A. L., \& Snyder, C. R. (1995). Gender differences in coping: A further test of socialization and role constraint theories. Gender Roles, 33, 25-35.

Stevens, N. (1995). Gender and adaptation in later life. Ageing and Society, 15, 37.

Stone, A. A., \& Neale, J. M. (1984). New measures of daily coping: Development and preliminary results. Journal of Personality and Social Psychology, 46, 892-906.
Stroebe, M. (1992). Coping with bereavement: A review of the grief work hypothesis. Omega: Journal of Death and Dying, 26, 19-42.

Stroebe, M., \& Schut, H. A. W. (1995, April). Differential patterns of coping with bereavement between widows and widowers. Paper presented at the annual conference of the British Psychological Society, Warwick, England.

Stroebe, M., \& Schut, H. A. W. (1999). The dual process model of coping with bereavement: Rationale and description. Death Studies, 23, 197-224.

Stroebe, M., Schut, H., \& Stroebe, W. (1998). Trauma and grief: A comparative analysis. In J. H. Harvey (Ed.), Perspectives on loss: A sourcebook (pp. 81-96). Philadelphia: Brunner/Mazel.

Stroebe, M., \& Stroebe, W. (1983). Who suffers more? Sex differences in health risks of the widowed. Psychological Bulletin, 93, 297-301.

Stroebe, M., \& Stroebe, W. (1989). Who participates in bereavement research? A review and empirical study. Omega: Journal of Death and Dying, 20, 1-29.

Stroebe, M., \& Stroebe, W. (1991). Does "grief work" work? Journal of Consulting and Clinical Psychology, 59, 479-482.

Stroebe, M., \& Stroebe, W. (1993). The mortality of bereavement: A review. In M. Stroebe, W. Stroebe, \& R. O. Hansson (Eds.), Handbook of bereavement: Theory, research, and intervention (pp. 175-195). New York: Cambridge University Press.

Stroebe, M., Stroebe, W., Gergen, K., \& Gergen, M. (1981). The broken heart: Reality or myth? Omega: Journal of Death and Dying, 12, 87-105.

Stroebe, M., Stroebe, W., \& Hansson, R. O. (Eds.). (1993). Handbook of bereavement: Theory, research, and intervention. New York: Cambridge University Press.

Stroebe, W., \& Stroebe, M. (1987). Bereavement and health. New York: Cambridge University Press.

Stroebe, W., \& Stroebe, M. (1993). Determinants of adjustment to bereavement in younger widows and widowers. In M. Stroebe, W. Stroebe, \& R. O. Hansson (Eds.), Handbook of bereavement: Theory, research, and intervention (pp. 208-226). New York: Cambridge University Press.

Stroebe, W., Stroebe, M., \& Abakoumkin, G. (1999). Does differential social support cause gender differences in bereavement outcome? Joumal of Applied Social and Community Psychology, 9, 1-12.

Stroebe, W., Stroebe, M., Abakoumkin, G., \& Schut, H. A. W. (1996). The role of loneliness and social support in adjustment to loss: A test of attachment versus stress theory. Journal of Personality and Social Psychology, 70, 1241-1249.

Stroebe, W., Stroebe, M., \& Domittner, G. (1988). Individual and situational differences in recovery 
from bereavement: A risk group identified. Journal of Social Issues, 44, 143-158.

Stroebe, W., Stroebe, M., \& Schut, H. A. W. (1993, October). Working through loss: Does it help? Paper presented at the annual conference of the Society for Experimental Social Psychology, Santa Barbara, CA.

Suls, J., \& Fletcher, B. (1985). The relative efficacy of avoidant and nonavoidant coping strategies: A meta-analysis. Health Psychology, 4, 249-288.

Thoits, P. A. (1986). Multiple identities: Examining gender and marital status differences in distress. American Sociological Review, 51, 259-272.

Thoits, P. A. (1991). Gender differences in coping with emotional distress. In J. Eckenrode (Ed.), The social context of coping (pp. 107-138). New York: Plenum.

Thompson, L. W., Breckenridge, J. N., Gallagher, D., \& Peterson, J. A. (1984). Effects of bereavement on self-perceptions of physical health in elderly widows and widowers. Journal of Gerontology, 39, 309-314.

Traue, H. C., \& Pennebaker, J. W. (Eds.). (1992). Emotion inhibition and health. Seattle, WA: Hogrefe \& Huber.

Umberson, D., Wortman, C. B., \& Kessler, R. C. (1992). Widowhood and depression: Explaining long-term gender differences in vulnerability. Journal of Health and Social Behavior, 33, 10-24.

U.S. Department of Health and Human Services, Public Health Service. (1985). Vital statistics of the United States, 1985. Washington, DC: U.S. Government Printing Office.

Van Grootheest, D. S., Beekman, A. T. F., Broesse van Groenou, M. I., \& Deeg, D. J. H. (1999). Gender differences in depression after widowhood: Do men suffer more? Social Psychiatry and Psychiatric Epidemiology, 34, 391-398.

Verbrugge, L. M. (1979). Marital status and health. Journal of Marriage and the Family, 41, 267-285.

Verbrugge, L. M. (1989). The twain meet: Empirical explanations of gender differences in health and mortality. Journal of Health and Social Behavior, 30, 282-304.
Verbrugge, L. M., \& Wingard, D. L. (1987). Gender differentials in health and mortality. Women and Health, 12, 103-145.

Vingerhoets, A. J. J. M., \& van Heck, G. L. (1990). Gender, coping and psychosomatic symptoms. Psychological Medicine, 20, 125-135.

Ward, A. W. (1976), Mortality of bereavement. British Medical Journal, 1, 700-702.

Weidner, G., \& Collins, L. (1993). Gender, coping and health. In H. W. Krohne (Ed.), Attention and avoidance (pp. 241-265). Seattle, WA: Hogrefe \& Huber.

Weisman, M. M., \& Klerman, G. L. (1977). Gender differences and the epidemiology of depression. Archives of General Psychiatry, 34, 98-111.

Weiss, R. (1975), Loneliness: The experience of emotional and social isolation. Cambridge, MA: MIT Press.

Williams, D. R., Takeuchi, D. T., \& Adair, R. K. (1992). Marital status and psychiatric disorders among Blacks and Whites. Journal of Health and Social Behavior, 33, 140-157.

Wingard, D. L. (1984). The gender differential in morbidity, mortality, and lifestyle. Annual review of public health (Vol. 5, pp. 433-458). Palo Alto, CA: Annual Reviews.

Wortman, C., \& Silver, R. (1987). Coping with irrevocable loss. In A. Baum, C. Frederick, I. Frieze et al. (Eds.), Cataclysms, crises, and catastrophes: Psychology in action (pp. 189-235). Washington, DC: American Psychological Association.

Wortman, C., \& Silver, R. (1989). The myths of coping with loss. Journal of Consulting and Clinical Psychology, 57, 349-357.

Young, M., Benjamin, B., \& Wallis, C. (1963). Mortality of widowers. Lancet, 2, 454-456.

Zech, E. (2000). The effects of the communication of emotional experiences. Unpublished doctoral dissertation, University of Louvain-la-Neuve, Louvain, Belgium.

Received November 22, 1999

Revision received May 16, 2000 Accepted May 16, 2000 